tures of engine speed, length of valve guide, diameter of valve stem, width of seat, fuel and mixture strength, ignition setting, and cooling water outlet temperature. These results are all interesting and some should prove of real practical use. One point to be particularly noticed is the statement that maximum engine temperatures were obtained when using normal mixtures with optimum ignition advance, a result quite contrary to the common belief that retarded ignition and weak mixtures give rise to overheating.

\section{Sound Recording for the Cinematograph}

T HE improvement in the quality of recorded sound during the past five or six years has been very rapid. During that time the silent film has been almost entirely superseded by the 'talkie' in the cinema. Dr. C. E. K. Mees, in the Sir Henry Trueman Wood Memorial Lecture delivered before the Royal Society of Arts on May 16, said that the introduction of sound recording to the cinema has influenced every part of the motion picture industry. While it will be readily appreciated that the various developments of the mechanisms for recording and reproducing pictures and sound have in themselves been very extensive, striking changes have also been made in other things, such as the design of theatres and the kind of play which may successfully be filmed.

The detail of sound recording and reproduction for the cinematograph may be divided into several sections : (1) Conversion of sound to electrical pulses ; (2) modulation of light intensity by the electrical pulses; (3) photographic recording of the light fluctuations; (4) light fluctuations reconverted to electrical pulses ; (5) electrical operation of the loud speaker. Much of this long chain of operations is concerned with electrical apparatus, but the photographic part differs in no essential way from the ordinary procedure of taking a snapshot, making and projecting a lantern slide. Each of the photographic processes calls, however, for very much more accurate control than is necessary for mere picture-making. Very extensive investigations have been made of the whole subject. These have covered many points already broadly understood, but the new work has been necessarily much more thorough.

The influence of the new knowledge gained is manifest in the improved quality of the sound in the theatres : there is less distortion and less 'ground noise'. Of the first of these it can only be said that constant research on the problems of making and matching negative and positive, and studying wave form reproduction, are gradually pushing the quality beyond its already high level. It seems, however, that little reduction in ground noise is to be expected from diminishing the grainy quality of the photographic material; the presence of minute scratches, dirt particles, etc., which are inevitably formed when the film is handled, is generally more than enough to counterbalance any decrease in graininess. The reduction of ground noise is being accomplished by modifying the recording apparatus so that the influence of flaws on the film is allowed to operate fully only when the sound to be recorded is loudest : the true sound record then masks the trouble.

The researches already carried out have necessitated the construction of much special apparatus and the development of special technique. Now that these are available, progress is likely to be even more rapid.

\section{University and Educational Intelligence}

London.-The following degrees have recently been awarded: D.Sc, in chemistry on H. Martin (Imperial College-Royal College of Science) for thirty-one published works on the "Elucidation of the Mechanism of the Toxic Action of Insecticides and Fungicides used for the Control of Crop Pests and Diseases"; D.Sc. in physiology on Dame Anne Louise McIlroy (University professor of obstetrics and gynæcology at the London (R.F.H.) School of Medicine for Women) for a thesis entitled "Researches upon the Prevention and Treatment of Asphyxia in the New-born" (Med. J. and Record, Nov. and Dec. 1933); D.Sc. in zoology on Ethelwynn Trewavas (private study) for published works entitled (1) "The Hyoid and Larynx of the Anura", (2) "Enteropneusta", (3) "A Revision of the Cichlid Fishes of the genus Lethrinops, Regan", (4) "Scientific Results of the Cambridge Expedition to the East African Lakes, 1930-31. II. The Cichlid Fishes", (5) "A Contribution to the Classification of the Fishes of the order Apodes, based on the Osteology of some rare Eels", (6) "On the Structure of two Oceanic Fishes, Cyema atrum, Gunther, and Opisthoproctus soleatus, Vaillant", together with three conjoint subsidiary contributions.

The American system of radio broadcasting was criticised in an address to the Ohio Radio Institute on May 2 by Levering Tyson, director of the National Advisory Council on Radio in Education. The actual situation is that while, from the engineering point of view, there has been remarkable progress, the programmes have no greater cultural value than before 1927 when a licensing authority was established. This authority has tended to crystallise the status quo so that the fundamental concept of broadcasting as a public service has been side-tracked and it remains an individualistic enterprise for private gain. The problems of educational broadcasting are no nearer solution than in 1929 when Secretary Wilbur appointed a committee to investigate them, and the number of educational stations has decreased steadily until to-day there are only a few dozen. Mr. Tyson anticipates that an effort will be made by the industry to put its house in order but that advertisement will continue to be its financial basis. He looks for a gradual assumption by the State of responsibility for establishing certain public services within or parallel to the industry but he holds that "you can't force intellectuality down democracy's throat unless it opens wide its mouth. So far its teeth have been tightly clenched". The address is reproduced in School and Society of June 30 .

Education in Kent, 1928-1933, is reviewed by the director, Mr. E. Salter Davies, in a report recently published by the County Education Committee. The administrative machinery was subjected to a severe strain in 1931, when expenditure had to be drastically restricted, and withstood the strain well, thanks to the elasticity and resiliency produced by a happy co-operation of its component parts and broad. minded and vigorous leadership. There was a notable rapprochement between the educational system and the requirements of industry. One of many instances of this is to be found in the ample provision for 
practical work of all kinds now made in the central schools, recently established under the Hadow reorganisation scheme. In these, science teaching has developed on lines that represent a marked improvement on the traditional method of teaching in elementary schools. It is based on the study of everyday phenomena and is therefore influenced more and more by the nature of the occupations of the local community. This method of approach from practice to theory, from the qualitative to the quantitative, is found to vitalise the teaching. Adaptation to local conditions is facilitated by the schools not having to prepare for any set form of examination, efficiency being assessed "by inspection which envisages individual initiative and free development rather than by an examination which would tend to stereotype the instruction given throughout the county". Conditions in the central schools provide, of course, increased opportunity for specialisation accompanied by the assumption by teachers of increased responsibility. So far the results have been wholly satisfactory, especially in attracting teachers of comparatively high qualifieations. Among ehanges in secondary education is the almost complete displacement of botany in girls' schools by biology, which has moreover found a place as part of the general science course in many boys' schools. Thirty pages of the report are devoted to agricultural education, in which Kent is pre-eminent.

\section{Science News a Century Ago}

\section{Death of General Paixhans (1783-I834)}

On August 19, 1834, General Henri Joseph Paix. hans, the distinguished French artillery officer, died near Metz. Born at Metz on January 22, 1783, he passed through the École Polytechnique and, entering the army, eventually rose to the rank of general. He was an experimenter and inventor, and he improved both guns and projectiles, while his views on the armament of men-of-war had a profound influence on the development of the French navy. $\mathrm{He}$ was one of the first to explore the possibility of protecting ships with iron armour plates. $\mathrm{He}$ wrote several technical works, among the most important of which were his "Nouvelle Force Maritime et Artillerie", 1822, and "Experiences faites sur une Arme Nouvelle", 1825. As a member of the French Chamber of Deputies, he made several important speeches which were afterwards collected and pub. lished.

\section{Caledonian Horticultural Society}

"The Society intended so to have arranged their annual dinner, as that the competition fruit might have been partaken of by the members of the British Association, who are to meet in Edinburgh on Sept. 7. On mature consideration, however, they found that they could not deviate from the day fixed in their prize list, which had been widely circulated six months before. This day is the 4 th of September, and if any of the learned strangers should happen to be in Edinburgh by that time, there is every reason to believe that they will be invited to be present at the Society's dinner. All the gardeners in the neighbourhood are exerting themselves to make a fine display by the time the Association arrive in Edinburgh." (Edinburgh Advertiser, Aug. 22, 1834.)

\section{Steam Carriages and Steam Boats}

The Mechanic's Magazine of August 23, 1834, said : "Mr. Hancock commenced on Monday last running two steam-carriages regularly between the City and Paddington, and they have been plying regularly throughout the week with uninterrupted success. One of Mr. Russell's steam-carriages between Glasgow and Paisley, having been overset by the breaking of a wheel, the boiler burst, and five persons were killed. The Court of Session has, in consequence of this, interdicted the whole set of carriages from running-for the present at least. A fine specimen this of Caledonian wisdom! Why do they not clear the Clyde of the whole of its steamers, since certain it is that steam-boats have met with accidents as well as steam carriages, and are as likely to meet with them again. It is impossible so absurd an edict can stand."

\section{Airy and Greenwich Observatory}

In his autobiography Airy says : "On Aug. 25th Mr. Spring Rice [Lord Monteagle] wrote to me to enquire whether I would accept the office of Astronomer Royal if it were vacant. I replied (from Keswick) on Aug. 30th expressing my general willingness, stipulating for my freedom of vote, etc., and referring to my letter to the Duke of Sussex. On Oct. 8th Lord Auckland, First Lord of the Admiralty, wrote : and on Oct. 10th I provisionally accepted the office. On Oct. 30th I wrote to ask for leave to give a course of lectures at Cambridge in case that my successor at Cambridge should find difficulty in doing it in his first year: and to this Lord Auckland assented on Oct. 31st. All this arrangement was for a time upset by the change of Ministry which shortly followed." At Keswick, between August 22 and August 29, Airy records also that he wrote his paper "On the Calculation of Perturbations" for the Nautical Almanac.

\section{'The 'Magneto-Electric' Spark}

On August 25, 1834, Faraday wrote in his Diary : "To-day procured the Electric spark from a Magnet directly, i.e. used no soft iron lifter or intermediate magnet". $\mathrm{He}$ described an experiment with a cylindrical bar magnet and a coil of wire wound on to part of a pasteboard tube, in which a wire from one end of the coil made contact against a small amalgamated metal plate attached to the other end, and the magnet, on being driven through the tube, separated the wire from the plate and a spark resulted. "The Electricity here is much more directly from the magnet than in the usual way of procuring a spark."

The entry needs some explanation. Faraday depended greatly on the spark as a means of showing that the induced currents he had discovered in 1831 really were electricity, having the same properties as that from a voltaic battery or frictional machine. At the time of reading of the First Series of the Experimental Researches in November 1831, he had succeeded in obtaining the spark by induction only with the iron ring and wire coils used in his original experiment of August 29. It was not until February 1832 that he found a way of producing it with a permanent magnet, by bringing the ends of an iron core, surrounded by a wire coil the ends of which were touching, down on to the poles, when a spark resulted at the contact of the wires. Now, in August 1834, he had eliminated the iron core and obtained his spark with magnet and coil alone. 